\title{
Two Step Conversion of Ferulic Acid to Vinyl Phenol
}

\author{
Meena Krishania*, Bhuwan B Mishra and Rajendra S Sangwan \\ Center of Innovative and Applied Bioprocessing, India
}

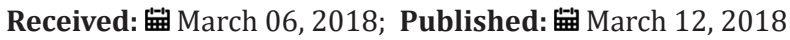

*Corresponding author: Meena Krishania, Center of Innovative and Applied Bioprocessing (CIAB), Sector-81, S.A.S Nagar, Mohali, Punjab140306, India, Email: er.mkrishania@gmail.com

\begin{abstract}
The cereal industries produce several million tons of cereal brans every year which are good source of ferulic acid. There was no such chemical route to convert ferulic to vinyl phenol directly. Therefore, an alternative approach two step conversion of ferulic acid to vinyl phenol was developed for better and costly flavour by using chemical route to make it cost effective.
\end{abstract}

Keywords: Ferulic acid; Vanillin; Vinyl phenol; Flavour

\section{Introduction}

Cereal brans are good source of ferulic acid. An approximate global production of 150 million tons of cereal brans have been reported in 2004. These by-products are extensively used as animal feed, but active research is being carried out in this field to produce higher value added products from these. Many literature review assesses the various biotransformations of ferulic acid and the role of microorganisms and plant cells in bringing about these transformations but no one have focussed to convert Ferulic acid to vinyl phenol chemically in two step system.

Ferulic acid is also a precursor for 4-vinyl guaiacol (3- methoxy 4-hydroxystyrene), the transformation being catalyzed by the enzyme ferulic acid decarboxylase. 4-vinyl guaicol or vinyl phenol is nearly 25-30 times more costly than ferulic acid which makes the conversion, a highly value added process. 4-vinyl guaiacol and other vinyl phenols may be produced from free phenolic acids and contribute to either the desirable aroma of important food products. 4-vinyl phenol has clove or spice like and phenolic flavour characteristics and is an appreciable flavour constituent in certain beers and soy sauce.

There were few studies on chemical route to convert ferulic to vinyl phenol majorly were reported by biological routes. Therefore, a fast and cost effective approach oftwo step conversion of ferulic acid to vinyl phenol was developed for valuable flavour by using cost effective chemical route.

\section{Methodology of Two Step Conversion of Ferulic Acid to Vinyl Phenol}

Scheme 1

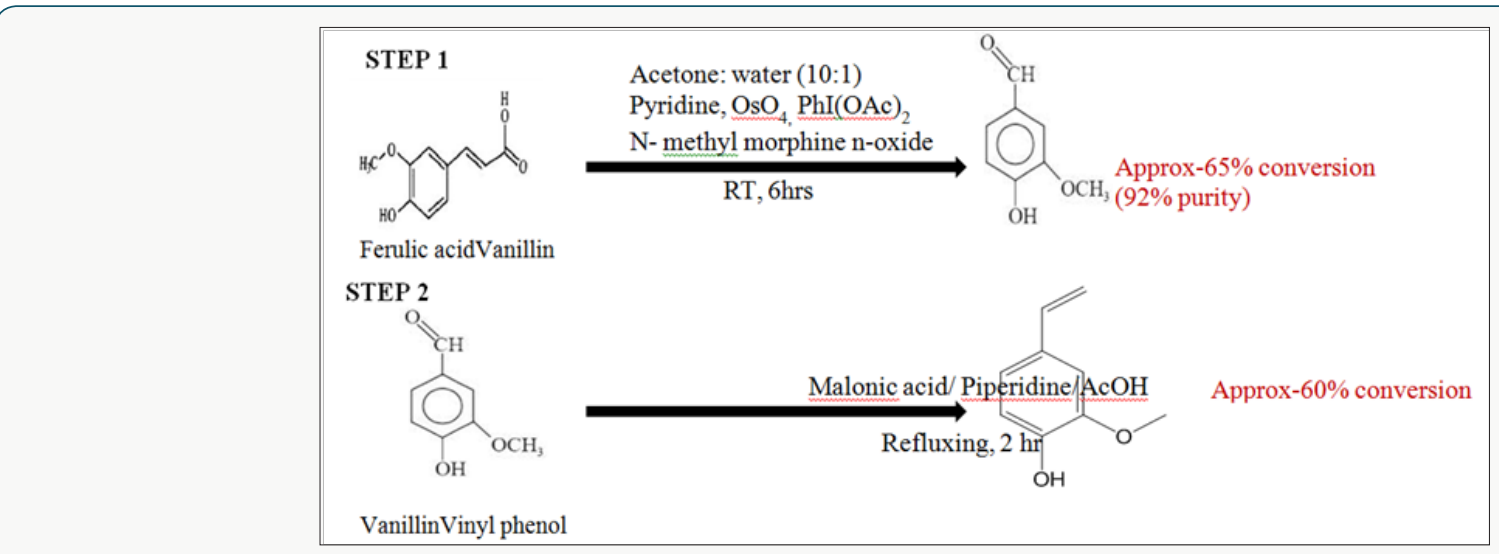

Scheme 1: Two step conversion of ferulic acid to vinyl phenol. 


\section{Result and Discussion}

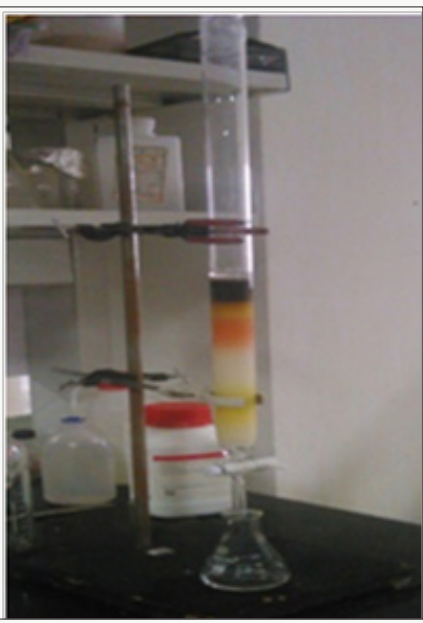

Figure 1: Purification by silica gel column.

In present study the innovative step is ferulic acid was initially converted to vanillin as shown TLC-1in fig 1 and then further it was converted to vinyl phenol. The process results into pure vanillin (Figure 1). Research efforts wereimposed to further convert the vanillin to vinyl phenol with improved quantity and quality (Figure 2). TLC-1 in Figure 3 shows the comparison of chemical spot of ferulic to vanillin and then in Fig 3 shows the TLC-2which presents the purity after flash silica gel column chromatography. Quantity was estimated by HPLC (Figure 4a \&4b) compared with standard vanillin (Sigma Aldrich). Vanillin purity was observed 92\% (w/w).

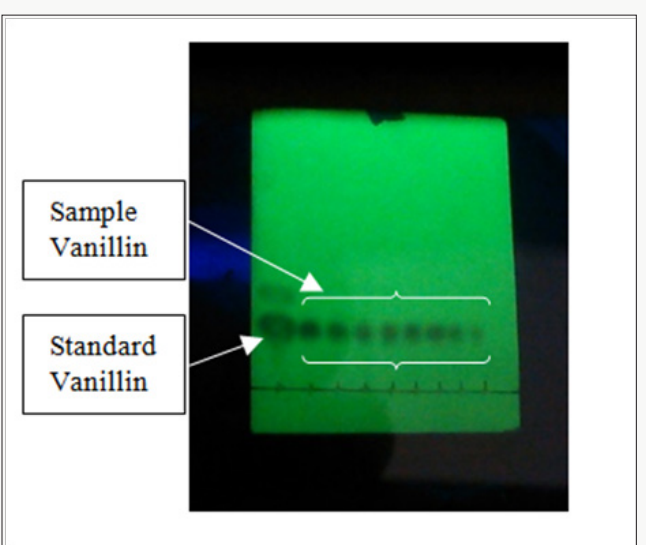

Figure 2: TLC-2 (Pure vanillin after column).

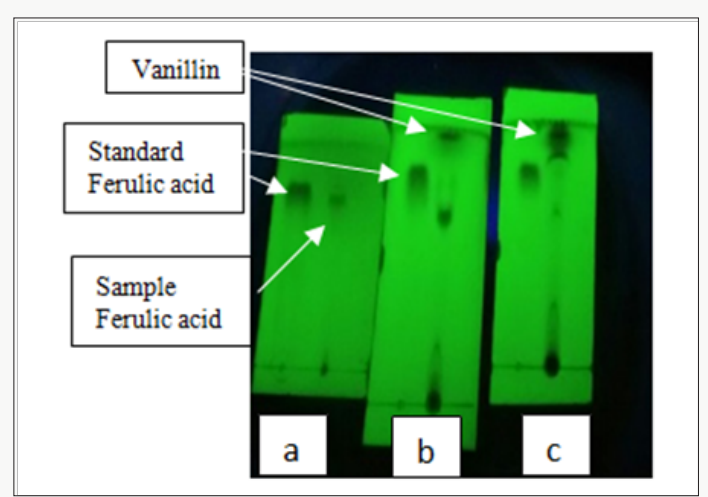

Figure 3: TLC-1 (Ferulic to Vanillin).
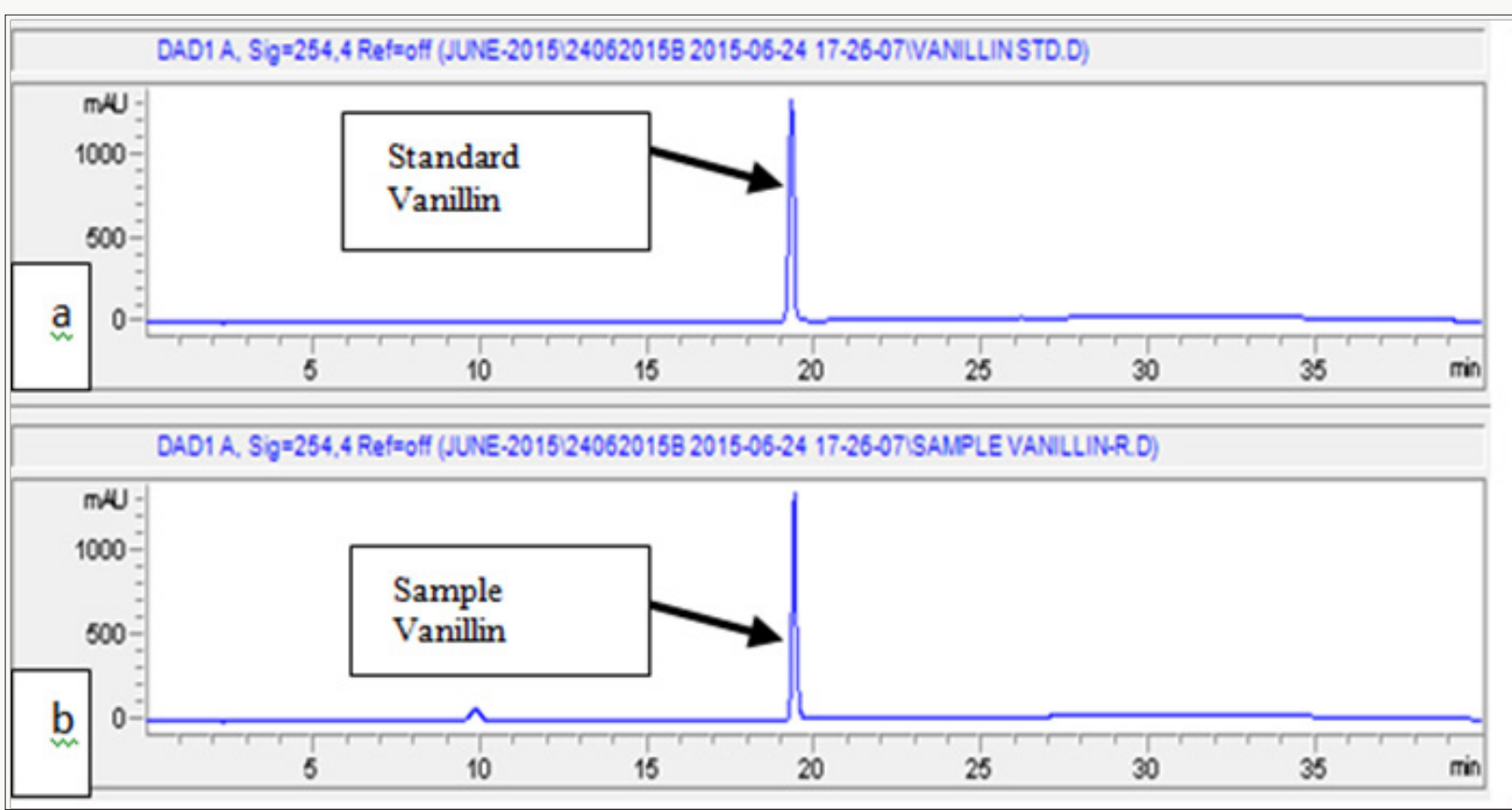

Figure 4: (a) Vanillin Standard and (b) Vanillin from Ferulic acid.

This sample vanillin was further converted to vinyl methoxy phenol as shown in figure 5. This is clearly visible from HPLC graph 


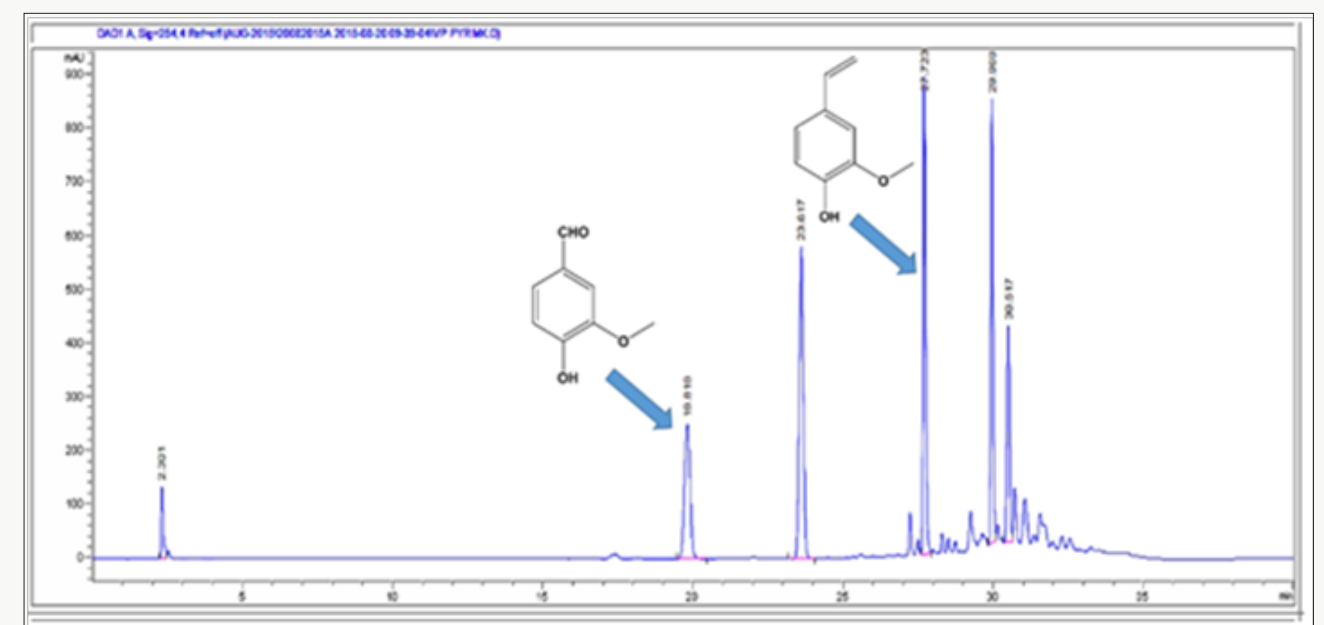

Figure 5: HPLC graph shows the conversion of vanillin to vinyl phenol.

\section{Conclusion}

Pure (92\%) vanillin was obtained and shows the $65 \%$ conversion of vanillin from Ferulic acid. The vanillin was further converted to vinyl phenol with $60 \%$ conversion in second step. This scheme can be test for large scale for further studies.
(C) (P) This work is licensed under Creative

To Submit Your Article Click Here: Submit Article

DOI: 10.32474/AOICS.2018.02.000130

\section{AOICS}

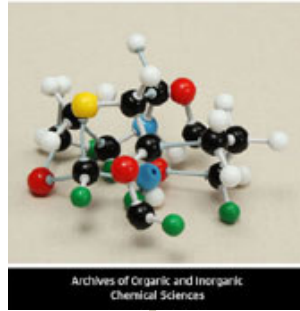

\section{Archives of Organic and Inorganic} Chemical Sciences

Assets of Publishing with us

- Global archiving of articles

- Immediate, unrestricted online access

- Rigorous Peer Review Process

- Authors Retain Copyrights

- Unique DOI for all articles 